\title{
ANÁLISE ESTRATÉGICA DO RELEVO E PLANEJAMENTO TERRITORIAL URBANO: COMPARTIMENTOS AMBIENTAIS ESTRUTURANTES NA MACROMETRÓPOLE DE SÃO PAULO
}

\author{
José Guilherme Schutzer \\ * Geógrafo pela FFLCH/USP, mestre em urbanismo pela FAU/USP, doutor em Geografia Física pela \\ FFLCH/USP, consultor em planejamento territorial e ambiental e professor de Desenho da Paisagem \\ na Associação Escola da Cidade. Email: jgschutzer@gmail.com.
}

\section{RESUMO}

O grande espalhamento urbano ocorrido nas regiões metropolitanas mundiais, ainda em intenso movimento de expansão urbana sobre antigos territórios rurais, colocou em evidência que os problemas ambientais que mais impactam os territórios, hoje, são os decorrentes dos processos de urbanização intensiva. Nesse sentido, a decisão sobre onde e como ocupar um território deve perpassar uma outra análise sobre o relevo, não mais apenas como um elemento estático e passivo, que se amolda aos diversos usos urbanos solicitados, mas com uma abordagem estratégica vinculada ao planejamento territorial e ambiental urbano. Ao destacar as principais linhas e compartimentos ambientais estruturantes de uma paisagem, sob o aspecto do relevo e dos processos de sua esculturação, pode-se entrever melhor as relações que os processos urbanos e suas infraestruturas impostas estabelecem com essas porções estratégicas da paisagem, podendo direcionar, assim, formas de uso e de ocupação do relevo mais condizentes com os processos urbanos e naturais, objetivando a eleição dos principais setores do relevo destinados aos serviços ambientais da preservação dos espaços de ocorrência dos processos naturais.

Palavras-chave: Planejamento ambiental urbano, geomorfologia urbana, desenho da paisagem, meio ambiente, compartimentos ambientais da paisagem. 


\title{
STRATEGIC ANALYSIS OF TOPOGRAPHY AND URBAN LAND PLANNING: \\ STRUCTURING ENVIRONMENTAL COMPARTMENTS IN MACRO-METROPOLIS OF SÃO PAULO
}

\begin{abstract}
The great urban spreading occurred in metropolitan areas worldwide, still in intense movement of urban expansion on old rural areas, evidenced that the environmental problems, which most affect the territories nowadays, are the result of intensive urbanization processes. In this sense, the decision about where and how to occupy a territorial area must pass through a different analysis on the topography, not anymore as just as static and passive element, which conforms to the several urban uses requested for a strategic approach linked to the urban territorial and environmental planning. By highlighting the main lines and environmental structuring compartments of a landscape under the topographic aspect and the processes of its geomorphologic form, it is possible to better glimpse the relationships urban processes and imposed infrastructures establish with these strategic landscape portions, which allow to define ways of use and land occupancy more suitable to urban and natural processes, aiming the selection of the main topographic sectors designated to environmental services for preservation of spaces of natural processes occurrence.
\end{abstract}

Key words: Urban Environment Planning, Urban Geomorphology, Landscape Design, Environment, Landscape Environmental Compartments.

\section{INTRODUÇÃO}

Abordar a categoria relevo nas relações entre sociedade e natureza tem sido objeto dos planejadores do espaço territorial brasileiro, em diferentes escalas de projeto de intervenção urbana.

$\mathrm{Na}$ escala regional, o relevo tende a ser abordado de forma mais generalista, observando o conjunto de unidades, caracterizadas por suas formas ou grandes compartimentos, como planaltos, serras e planícies. São os grandes conjuntos que são analisados, sobretudo ante as formas de ocupação econômica, entendendo-se que as formas de ocupação agrária são as que mais se relacionam com as alterações fisiográficas e fisionômicas da paisagem, dando menor relevância para os efeitos da urbanização do território. 
Já na escala local, a tendência recai sobre a investigação da cidade e da zona rural próxima, aquela de interesse periurbano, ou de expansão urbana. Nesta escala, observa-se a ocupação das vertentes e dos fundos de vale inseridos nos relevos de morros, colinas e planícies. Assim, analisam-se setores de um conjunto de formas de relevo, individualizadas em espigão, morros, colinas, várzeas, terraços, fundos de vale, dando-se pouca atenção aos conjuntos de relevo que exercem um maior controle sobre os processos de funcionamento da paisagem.

O relevo é tratado, tanto na escala regional como na local, sob o enfoque antropocêntrico (Casseti, 1995, p. 35), tido como um recurso natural, mas importante naquilo que ele desempenha para o homem, inserido em um território e parte constituinte deste. Dessa forma, sua análise tem significância, quando a abordagem se relaciona com o território usado, sinônimo de espaço geográfico, portanto, categoria de análise geográfica. (Santos, 2008, p. 19).

É fato que o relevo deve ser entendido como herança de processos passados, naturais e sociais, e como recurso atual da sociedade, mas também como herança para as sociedades futuras. Neste sentido, ganha relevância a análise das formas de ocupação e de utilização do território, e, contidas dentro dessa categoria, as formas de utilização e de apropriação do relevo.

Como os usos são diferentes, nos diversos momentos da história das sociedades, cada um carrega um peso diverso, entre novidade e heranças registradas nas formas do relevo e da paisagem (Santos, 2008, p. 20). O uso do território se intensificou, a partir do início do século passado, à medida que o crescimento populacional explodia em termos mundiais. Com a intensificação da urbanização, a partir da segunda metade do século $\mathrm{XX}$, um número cada vez menor de lugares passa a abrigar um número cada vez maior de pessoas, significando uma maior divisão do trabalho e, ao mesmo tempo, uma imobilização relativa, que é também resultado de uma fluidez aumentada no território. (Santos, 2008, p. 21).

Nesse contexto, a urbanização modifica seu conteúdo, alterando e imobilizando uma maior parte do território, diminuindo e restringindo os espaços de domínio dos objetos da natureza, incluindo até a restrição dos espaços agrários (rurais).

O relevo é apropriado cada vez mais, e com mais intensidade, pelos usos urbanos. No contexto da cidade moderna, da organização territorial alinhada a um controle cen- 
tralizado e hierarquizado das redes urbanas, decorreu uma tendência à compactação da mancha urbana da cidade e das áreas que se metropolizavam. Já no contexto da cidade contemporânea, descentralização e dispersão caracterizam o desenho das funções e morfologia da ocupação em curso'. No primeiro caso, todos os compartimentos do relevo, desde várzeas, fundos de vale, variados tipos de vertentes, topo de morros de diversos matizes, foram sendo ocupados pelos usos e funções nitidamente urbanas. No segundo, fragmentos do mundo rural ou natural (incluindo a segunda natureza) vão figurando em espaços intersticiais à ocupação que se efetiva, em face da fluidez aumentada sobre o território. Neste contexto, as infraestruturas de mobilidade tendem a imobilizar uma porção cada vez maior de áreas urbanas e rurais, e ampliam sua interferência sobre o relevo e sobre as condições ambientais, sobretudo em virtude de sua natureza linear.

Como acentuou Soja (1994, p. 154),

[...] as dinâmicas do desenvolvimento metropolitano já não são, hoje, tão decididamente monocêntricas, tão determinadas por um modo singularmente polarizado de forças centrífugas e centrípetas, por um padrão de crescimento urbano que gira em torno de um centro definitivo da cidade.

Disso decorre uma expansão horizontal sem precedentes da urbanização, e um impacto sobre o relevo e sobre o ambiente local, também, até então, não imaginável.

A urbanização extensiva sobre o território, no contexto abordado por Monte-Mór (1994), também impulsionou um redirecionamento do próprio entendimento do conceito de natureza e da sua relação com a sociedade. É nesse sentido que é possível afirmar, como Santos (1994, p. 15), que hoje a natureza é histórica, inclusive o chamado "meio ambiente", e que seu valor local se torna relativo, ou, em todo caso, relativizado. Assim é que, quando jovens, percebíamos como natureza uma paisagem rural já totalmente modificada pela ação humana.

O homem torna-se, na atualidade, um dado da valorização dos elementos naturais, porque é capaz de ação. O sistema natureza ganha, assim, um novo significado. É

1 Essas características foram analisadas em capítulo da tese de doutorado - "Dispersão urbana e apropriação do relevo na macrometrópole paulista" - apresentada à FFLCH-USP, em agosto de 2012. 
nesse sentido que Santos (1988, p. 90) argumenta que "o homem é sujeito, enquanto a terra é objeto", pois ele utiliza "suas forças intelectuais e físicas contra um conjunto de objetos naturais que seleciona como indispensáveis para se manter enquanto grupo". Mas, se o homem tem poder de modificar a intensidade da ação das forças da natureza, esta também impõe aos grupos humanos a necessidade de adaptações, ou seja, em qualquer escala da intervenção humana sobre a natureza, o progresso técnico não elimina a ação da natureza e algumas das imposições territoriais, dentre elas, a de certas situações do relevo (Santos, 1988, p. 91)

\section{A COMPARTIMENTAÇÃO DA PAISAGEM COMO ETAPA PARA A SÍNTESE DA PAISAGEM E DO RELEVO}

Na integração das diversas leituras temáticas que se podem extrair de uma paisagem, ou de um território, a sobreposição de cartas, mapas físicos e das infraestruturas existentes é um dos recursos utilizados, para se distinguir unidades de paisagens, segundo suas características físicas e critérios de homogeneidade ou heterogeneidade. Não se pode negar certa dose de interpretação contida neste método, em virtude da visão seletiva de quem analisa os diversos layers que carregam as informações daquela paisagem.

Tem-se denominado "unidades de paisagem" às separações e agrupamentos de tipologias afins, sejam elas de padrão uniforme ou complexo. Essas unidades de paisagem são distinguidas segundo as variadas categorias selecionadas para a análise, desde as que se baseiam predominantemente nos aspectos físicos, ou em parte dos elementos físicos da paisagem, até as abordagens que incluem temas do universo social e econômico da paisagem estudada.

De outro lado, na produção de sínteses interpretativas da base física, um recurso costumeiramente utilizado na Geografia Física e na Geomorfologia tem sido a compartimentação preliminar do relevo, incluindo o estudo de suas formas, como método de simplificar a leitura da paisagem observada em poucas unidades tipológicas, para que delas se possam extrair elementos que se constituam em premissas de abordagens propositivas. Para Ab'Saber (1975), "toda paisagem possui uma certa compartimentação de relevo". Como a superfície do planeta apresenta porções de território altas e

2 O homem não comanda as intempéries, mas tem conhecimento prévio de sua eclosão. (Santos, 1988, p. 92) 
baixas, formas aguçadas ou planas, homogêneas ou complexas quanto à ocorrência de suas formas, é relativamente fácil extrair do relevo uma leitura de seus compartimentos. Numa primeira aproximação, pode-se dizer que essa leitura está representada por aquilo que se convencionou designar por planaltos, planícies e serras.

Dessa forma, entende-se, por compartimento de relevo, qualquer conjunto topográfico situado entre áreas topograficamente mais elevadas, ou aqueles situados entre áreas topograficamente mais baixas. (Ab'Saber, 1975). É claro que esse primeiro escalonamento do relevo assume características internas diferenciadas, em função das cotas de altitude predominantes, da estrutura superficial da paisagem e da ossatura geológica que o sustenta, bem como dos diversos arranjos de padrão de formas de relevo, passíveis de ocorrer em função das dinâmicas climáticas atuais e pretéritas.

Em Geomorfologia, segundo Ab'Saber (1969), o que se pretende com a compartimentação do relevo vai um pouco além do mero escalonamento topográfico da superfície. Ele entende que "desde que se faça também o estudo dos diferentes tipos de depósitos superficiais e considerações adequadas sobre sua significação paleogeográfica", o que se almeja mesmo é um estudo da compartimentação da paisagem, sendo estes compartimentos derivados de uma gênese evolutiva desencadeada pelos processos de funcionamento da paisagem pretérita e pelos processos atuais que possam indicar tendências evolutivas futuras.

Assim, toda paisagem pode ser dividida em compartimentos, setores e unidades, segundo critérios que se estabelecem para a análise a ser empreendida.

\section{A COMPARTIMENTAÇÃO TOPOGRÁFICA}

A compartimentação topográfica é uma técnica de abordagem do relevo, e um nível de pesquisa considerado elementar na Geomorfologia, embora muitos pesquisadores desconsiderem a importância dessa análise preliminar da paisagem, nos estudos geomorfológicos. É certo que, muito além do que havia expressado Ab'Saber, em 1969 (p. 3), quanto ao extraordinário desenvolvimento da cartografia àquela época e a disponibilidade de cartas topográficas e fotografias aéreas, não há muito o que fazer no campo da compartimentação dos terrenos, pois as ferramentas de que se dispõe facilitam sobremaneira a visualização da compartimentação topográfica de uma paisagem, em um nível muito superior ao obtido pelo trânsito na área. 
Ab'Saber, defensor desse método básico de pesquisa geomorfológica, explicava, em 1969 (Ab'Saber, 1969, p. 3-4), a importância dessa abordagem do relevo, para a interação com as disciplinas vizinhas, bem como para facilitar a compreensão do relevo e sua dinâmica, pelos profissionais de diversos ramos do saber implicados com o planejamento e o uso do território. Para esse autor, a compartimentação topográfica se relaciona com os níveis topográficos e com os depósitos superficiais ou estruturas rochosas do embasamento, e também com a posição relativa entre eles. É por isso que fica implícito, no estudo da compartimentação topográfica da paisagem, aspectos da própria fisiologia da paisagem. Por isso, a importância e a validade do método, conforme sugeria Ab'Saber.

$\mathrm{Na}$ Geomorfologia, a compartimentação topográfica corresponde à individualização de um conjunto de formas com características semelhantes, em que se admite que tenham sido elaboradas em determinadas condições morfogenéticas ou morfoclimáticas parecidas, e/ou que apresentem relações litoestratigráficas oriundas de uma mesma gênese. A interpenetração das diferentes forças ao longo do tempo leva à individualização e à caracterização das formas de relevo, da situação topográfica ou altimétrica, bem como da existência de traços genéticos comuns.

A expressividade dessas forças atuantes na elaboração do modelado depende tanto da intensidade, quanto da duração dos fenômenos, e, nesse sentido, a compartimentação topográfica visa evidenciar o resultado dessas relações processuais e respectivas implicações tectônico-estruturais registradas ao longo do tempo, que tendem a originar formas diferenciadas, em face das alternâncias climáticas e das variações estruturais. Portanto a compartimentação topográfica visa, em suma, diferenciar conjuntos, por formas e processos atuantes.

Dentre os subsídios que a compartimentação do relevo, na perspectiva geomorfológica, oferece ao planejamento territorial urbano, destacam-se a vulnerabilidade e a potencialidade. Considera-se vulnerabilidade o indicador da suscetibilidade erosiva do relevo, tanto em condições naturais, quanto prognosticáveis, em função de determinados usos ou tipo de ocupação. Já a potencialidade tem a ver com determinadas individualidades, que podem ser racionalmente apropriadas para fins específicos, como o caso de áreas portadoras de depósitos de cobertura com fertilidade natural, destinadas a atividades agrícolas; ou o potencial mineral; ou ainda morfologias especiais, como as cársticas e falhadas, voltadas à exploração turística. 
A metodologia utilizada nos estudos de compartimentação do relevo depende da dimensão ou da escala do estudo, que deverá estar ajustada a um determinado nível taxonômico. Depende também dos objetivos e do nível de abordagem proposto para o estudo. A função da compartimentação é subdividir o relevo em unidades que permitam tratamento individual, em função de sua ordem de grandeza. Como já mencionado, essas unidades são representadas por meio de um conjunto de formas de relevo que guardam similitude e posição altimétrica individualizada, podendo ser divididas em subunidades que identifiquem particularidades regionais, pelo posicionamento altimétrico e fatores genéticos. A própria classificação do relevo apresentada desde os mapas escolares já se trata de uma compartimentação da paisagem. Planaltos, planícies, depressões são termos que evocam compartimentos de relevo.

A elaboração de perfis dessa compartimentação topográfica é uma prática associada à elaboração da cartografia geomorfológica, facilitando a visualização dos compartimentos e a posição relativa em que se encontram. A análise e descrição das formas de relevo associadas a cada compartimento proporcionam uma primeira aproximação mental e dedutiva, acerca da fisiologia da paisagem em operação naquela porção do território. Evidentemente, não é possível ao pesquisador a abordagem analítica dos complexos indicadores das ações morfológicas, pedogênicas e hidrodinâmicas integradas de uma paisagem. No entanto, a simples consciência desses fatos já constitui um bom ponto de partida, para iniciar o entendimento daquela paisagem.

\section{A COMPARTIMENTAÇÃO AMBIENTAL}

Diferente da compartimentação topográfica, a compartimentação ambiental introduz, de forma enfática, na compartimentação topográfica, a ideia de valores de uso e de ocupação do relevo para a sociedade urbana. À fisiologia da paisagem, que conduz a esculturação evolutiva do relevo, associa-se o funcionamento da sociedade, por meio do funcionamento da cidade e do campo, das ações humanas e do acréscimo de formas artificiais da engenharia humana. A compartimentação ambiental, na forma aqui analisada, visa associar, ao compartimento de relevo, sua aptidão ou fragilidade em responder às funções urbanas que lhe quer dar a sociedade. Portanto trata-se de um conceito de cunho eminentemente urbano, operacional, para avaliar e planejar a urbanização de um território. 
Não se quer dizer, com isso, que a compartimentação topográfica feita nos estudos de geomorfologia não relacione as fragilidades e potencialidades dos compartimentos para a sociedade. No entanto, trabalha com diretrizes gerais, enquanto a compartimentação ambiental visa subsidiar o desenho urbano e a urbanização do território, com uma leitura estratégica do relevo, para fins propositivos de escolha efetiva dos espaços a ocupar ou preservar.

Na realidade, as duas formas de compartimentação do relevo, a topográfica e a ambiental, parecem mesmo ser a mesma coisa. A compartimentação topográfica é uma etapa da análise ambiental. Ou seja, para se chegar a uma compartimentação ambiental, é necessário realizar uma primeira aproximação dela, que se faz por meio de uma compartimentação topográfica minuciosa. Somente após, introduz-se a análise valorativa dos compartimentos topográficos. Quais são suas potencialidades e fragilidades, para responder às necessidades de uso e ocupação do solo para fins urbanos e periurbanos? Não estamos falando aqui de necessidade de preservação ambiental, pois esta faz parte das necessidades de uso do território. Hoje já é compreensível, para a maior parte das pessoas, que o uso intensivo dos recursos da natureza requer espaços de preservação, dos recursos e dos processos naturais.

Então, quais são os valores associados à compartimentação ambiental da paisagem? Pode-se dizer que o valor central, para a sociedade, é a manutenção de certa estabilidade dos processos naturais, ou seja, um equilíbrio dinâmico e dialético entre os processos urbanos e processos naturais, que permita a sustentabilidade do território. Mas que sustentabilidade é essa? ${ }^{3}$

Se observarmos sob o ponto de vista do conceito de geossistema, é necessário garantir as propriedades sociorreprodutoras do sistema local, ou seja, assegurar espaços para a reprodução social do morar, trabalhar, ter lazer, produzir alimentos e recursos materiais (mineração, silvicultura etc., ou seja, propriedades geoeconômicas). Portanto, para que isto se dê, a pergunta que se faz deve versar sobre quais são os compartimentos de relevo que possuem maior ou menor aptidão para o desempenho dessas funções necessárias à sociedade, relativos ao espaço em que se está planejando o uso e ocupação. Qual é o seu potencial de uso ou de ocupação? Pode-se

3 Fazemos referência à sustentabilidade em um sentido genérico, referente à manutenção de certas condições de estabilidade da vida social em relação ao ambiente, à natureza. Não é intenção entrar no mérito da discussão de sustentabilidade, que, embora em voga e na moda, é bastante controverso e eivado de carga ideológica. 
até relacionar a esta pergunta qual é a segurança de seu uso, se pensarmos na corriqueira condição de ocupação destinada às populações de baixa renda, que habitam áreas alagáveis ou encostas sujeitas a riscos de deslizamento. Acrescente-se aqui, também, a presença de valores culturais instalados no compartimento, ou ainda aqueles relativos ao próprio valor sentimental de uma paisagem natural.

Por outro lado, a sustentabilidade do território também perpassa a garantia das propriedades geoecológicas da paisagem em uso e com planos de expansão. Aqui se fala das propriedades biofísicas da natureza, da qual o relevo faz parte. Trata-se de se perguntar quais compartimentos prestam serviços ambientais importantes para a sociedade, como o fornecimento de água potável, zonas de amenização climática por meio de florestas, bosques, lagos, ou por abrigar reservatórios etc. Inclui-se também a necessidade de manutenção da biodiversidade dos biomas, ou as áreas de refúgio de fauna ou de sua reprodução, refúgios da flora e outras potencialidades paisagísticas. Aqui se quer destacar a importância da manutenção dos recursos da natureza, mas também a dos processos naturais.

Portanto, na análise geomorfológica da compartimentação topográfica, a fim de se compreender a cinemática da paisagem, inquiria-se a fisiologia da paisagem, no que concerne a modelos predominantemente naturais ou de pouca interferência humana. Mesmo quando esta interferência existia, a análise tendia à constatação, e muito pouco à obtenção de prognósticos do futuro da paisagem.

Entendida desta maneira, a compartimentação ambiental poderá não coincidir com o detalhamento proposto pela compartimentação topográfica. Compartimentos topográficos diferentes poderão ter a mesma função para os interesses sociais, naquele momento, ou naquela sociedade. Assim, poderão configurar um só compartimento ambiental.

Percebe-se, desta forma, que a compartimentação ambiental é uma síntese da paisagem, naquilo em que esta interessa para a urbanização do território. Assim, compartimentos ambientais serão mais bem definidos nas áreas mais urbanizadas ou densamente povoadas, pois se faz necessária uma ordenação do uso do território, para explorar as potencialidades e preservar as áreas de maior fragilidade ambiental, ou necessárias à manutenção do equilíbrio urbano. Nas áreas pouco povoadas, ela também pode ser importante, no sentido de direcionar o crescimento e o uso do território, mas, em virtude da pequena escala da urbanização, ante os demais espaços agrários e naturais, a compartimentação ambiental perde relevância. Outros instrumentos, 
como o Zoneamento Econômico-Ecológico, são mais apropriados ao planejamento territorial de grandes regiões. Nas áreas fracamente povoadas, a condição é semeIhante, em termos de impactos ambientais, ao que ocorria, no passado, em cidades e áreas rurais de pequena expressão populacional, em que os impactos ambientais da urbanização (incipiente) eram plenamente absorvidos pela natureza local.

A compartimentação ambiental visa entender a fisiologia de cada compartimento e sua função na paisagem, os impactos que recebe de processos desenvolvidos em outros compartimentos, ou aqueles que induz ou provoca nos demais compartimentos da paisagem. Nesse sentido, interessa também, como valor ou necessidade, inquirir sobre o estágio de degradação da paisagem e do compartimento, e sua situação de resiliência.

Os compartimentos assim analisados podem sugerir estratégias e índices de uso e ocupação, ou até de preservação. Revelam, também, suas potencialidades para outros usos, que até então não haviam sido chamados a executar-se.

Nesse contexto, um aspecto importante, na análise da compartimentação ambiental, vem a ser a questão de sua abrangência em superfície, ou seja, da dimensão de cada compartimento ambiental, e de sua área de influência ou de impacto, seja negativo ou positivo, para a manutenção dos indicadores de qualidade ambiental. Cabe avaliar se um compartimento sofre impactos provenientes de muitos outros, ou de uma vasta área; ou, então, se o compartimento promove impactos a uma área relativamente grande. Nessa mensuração, concorre a análise da superfície de contato com a dinâmica do clima (radiação, chuvas, emissividade de calor, influência na circulação do ar) e com a dinâmica da água (escoamento, infiltração, percolação, erosão laminar, erosão), assunto já abordado por este autor no livro "Cidade e Meio Ambiente: a apropriação do relevo no desenho ambiental urbano" (Schutzer, 2012).

É certo que, muitas vezes, poder-se-á confundir a compartimentação ambiental da paisagem com a identificação de unidades de paisagem, conceito muito utilizado recentemente por geógrafos, arquitetos, urbanistas, biólogos e ecologistas de diversos matizes. E também com a definição de zoneamento ambiental e zoneamento econômico-ecológico. Ou, ainda, com as unidades geomorfológicas de uma paisagem, muitas vezes mais associada ao conjunto de formas de relevo homogêneas.

De fato, todos esses estudos se baseiam também na identificação das potencialidades e fragilidades, para fins de uso do território e de seus recursos para a sociedade, 
como subsídios à gestão do território. No entanto, há que se ressaltar diferenças de escala importantes. Como exemplo, cita-se o caso do Zoneamento Ecológico-Econômico da Amazônia Legal, que, mesmo fundamentado nos conceitos ecodinâmicos de Tricart (1977), tendo o relevo como componente básico, foi realizado em uma base cartográfica na escala 1:250.000, portanto, uma abordagem de nível regional, relacionando grandes diretrizes de utilização do território. Neste caso, realiza-se uma macrocompartimentação topográfica da paisagem. Dentro de cada conjunto, tem-se uma rede de cidades em desenvolvimento, em que cada componente da rede realiza sua relação dialética com um relevo local, pouco detalhado em seus compartimentos, em virtude da escala trabalhada (1:250.000).

Tanto a compartimentação topográfica, como a compartimentação ambiental não apresentam uma escala definida, pois dependem de cada situação regional e local da paisagem. Entretanto, para a compartimentação ambiental, há que se ter uma finalidade de uso urbano do território, senão ela perde sentido e utilidade. Portanto a compartimentação ambiental está intrinsecamente ligada às áreas de ocupação humana mais densa.

\section{COMPARTIMENTOS AMBIENTAIS ESTRUTURANTES}

Com base no exposto até aqui, é possível falar, então, de compartimentos ambientais estruturantes de uma paisagem. Estes se definem como aqueles que colaboram em maior grau para a preservação dos valores associados aos compartimentos do território estudado, sobretudo daqueles valores relativos às propriedades geoecológicas do território. Trata-se, assim, de uma avaliação estratégica do relevo e das condições físico-ecológicas, para fins de ocupação e de preservação, preservação essa em duplo sentido: a dos recursos de flora, fauna, água e solos férteis, e a da preservação dos processos naturais sem alterar em muito sua intensidade normal.

Vem agregada, a essa identificação, uma noção de escala de abrangência do compartimento estruturante dos processos naturais e urbanos, ou seja, aquele conjunto - compartimento ou setor dele - que mais interfere nos processos naturais da região estudada, e que mais colabora na preservação do equilíbrio natural-urbano e dos recursos naturais imprescindíveis à vida da cidade, como água potável, clima ameno, entre outros. Os compartimentos estruturantes são aqueles dos quais derivam influências (positivas ou negativas) aos demais compartimentos, ou então aqueles que re- 
cebem interferência de uma vasta área, de outros compartimentos, interferência essa em duplo sentido, o de impactos diretos e o da indução de processos.

São estruturantes, também, aqueles compartimentos que possam agregar condicionantes ecológicas importantes para a preservação da flora e da fauna associada, como a criação de corredores ecológicos, a junção de áreas de concentração de nascentes e seus anfiteatros, a preservação das margens (APPs) dos mais importantes canais de drenagem, a preservação das encostas íngremes de compartimentos que interferem na circulação dos ventos etc. Nesse sentido, um compartimento ambiental estratégico é aquele que colabora para combater a fragmentação da paisagem, no sentido da preservação dos biomas e habitats para a fauna, como também o que mais colabora para regulação da ocorrência dos processos naturais relativos às dinâmicas da água e do clima.

Qual deve ser, então, a posição de um compartimento estruturante, na paisagem? Como já mencionado, existem compartimentos que influenciam ou impulsionam a ativação ou a intensificação dos processos naturais de outros compartimentos. Como exemplo, podem ser citadas as regiões serranas; os grandes alinhamentos de divisores de água, que determinam a intensidade do escoamento superficial e interferem na circulação atmosférica; aqueles que regulam a oferta de água durante o ano etc. Existem aqueles outros compartimentos que recebem influência dos demais, ou de uma área expressiva, como as grandes várzeas ou planícies costeiras, ou embutidas em macrocompartimentos de planalto. O exemplo clássico dessa influência está na ocorrência das cheias naturais dos rios, ou nas enchentes que impactam a vida das cidades.

Dessa forma, existem compartimentos indutores de processos, e compartimentos receptores de processos, ou seja, para onde se dirigem e onde se concentram processos induzidos em áreas distantes de outros compartimentos.

A mensuração do tamanho da área de influência é, de certa forma, uma tarefa mais subjetiva, pois derivaria de estudos mais complexos e detalhados da fisiologia da paisagem, objeto dessa avaliação estratégica do relevo. É mais tranquila a determinação da influência indutiva ou passiva dos processos relativos à dinâmica da água, pois ela é dada e controlada, em boa parte, pela delimitação das bacias hidrográficas. Nesse sentido, tanto os divisores de água, quanto os fundos de vale receptores da água infiltrada, escoada ou percolada em seu entorno podem ter sua delimitação 
mais precisa. Para os divisores de água, serão os canais principais de drenagem de seu entorno. Para os fundos de vale, serão os divisores de água de seu entorno. Pode-se perceber, pela descrição, que essas delimitações podem se imbricar na paisagem, induzindo a avaliação da importância de toda essa região, na preservação dos processos naturais.

Já para a dinâmica do clima, essa mensuração é mais difícil, por isso, torna-se mais subjetiva, devendo ser balizada por indicadores que possuem implicações com a circulação atmosférica (barreiras ao vento e indução de chuvas orográficas, canalização dos ventos, na dispersão de poluentes, na conformação das ilhas de calor, nos índices de umidade relativa do ar, na mensuração da temperatura de superfície etc.).

Entre os dois elementos da paisagem citados, que configurariam compartimentos ambientais estruturantes, os divisores de água - indutores de processos - e os fundos de vale - receptores -, estão os setores de vertentes que interligam essas duas linhas estruturantes da paisagem. Essas vertentes podem ter declividades suaves ou elevadas, e são as áreas por onde passam e se desenvolvem os processos naturais. Seriam, assim, áreas receptoras e transmissoras, ao mesmo tempo, mas não somente, pois nelas também se desenvolvem processos naturais que induzirão impactos a jusante, ou seja, distribuindo-os para outros compartimentos. Portanto, embora se configurem em áreas mais passíveis de ocupação urbana, quando não muito íngremes, elas também devem ser objeto de regulação da forma e intensidade de sua ocupação, quando se constituam em indutoras de processos para outros compartimentos, principalmente para aqueles considerados estruturantes.

A percepção do relevo pelo homem sempre ressaltou esses dois elementos significativos de uma paisagem - os rios e os morros, vales e serras. Nestes, os grupos humanos buscavam definir seus caminhos, suas trilhas, aproveitando tanto os fundos de vale, como os alinhamentos de divisores, como percursos mais suavizados do relevo e com menores interrupções bruscas do caminho. São, portanto, compartimentos de relevo que sempre interessaram à mobilidade do homem, e por onde foram sendo implantadas as infraestruturas fixas de ferrovias, estradas, e, mais recentemente, rodovias e avenidas (fundo de vale). Buscavam, também, ora a proximidade com a água, ora a segurança das vistas de paisagem, o controle do território por meio de localizações escolhidas, de eixos visuais abrangentes. 


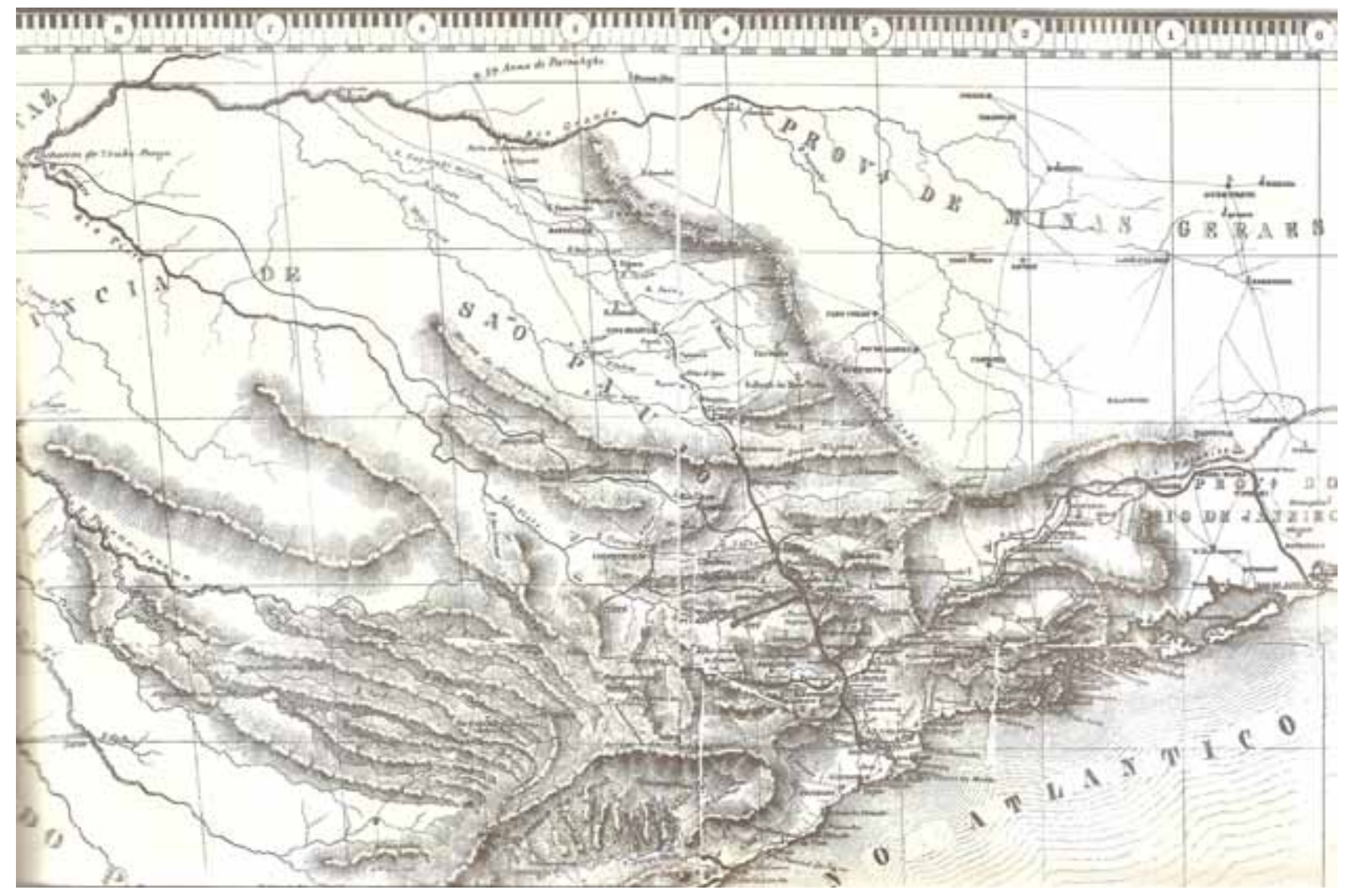

Figura 1 - Mapa Topográfico da Província de São Paulo - 1875. Fonte: Godoy (2007)

Nesse sentido, como ilustração, vale apreciar o mapa topográfico de 1875 (Figura 1), em que aparecem, em destaque, essas grandes linhas da paisagem, que sintetizavam, para a época, as feições mais relevantes do relevo, que se impunham como obstáculos ou como oportunidades. Observe a expressão dada ao desenho dos divisores de água das suaves colinas do interior, situadas na depressão Periférica. Tratava-se dos principais caminhos de penetração por terra, para o sertão de São Paulo, livres da transposição dos afluentes do rio Tietê e dos outros rios que tinham seu curso na direção do interior (noroeste). Ou, então, a partir da passagem do planalto Atlântico para a depressão Periférica, poder-se-ia atingir o interior do Brasil pelos rios navegáveis, como o rio Tietê.

\section{COMPARTIMENTOS AMBIENTAIS ESTRUTURANTES DA MACROMETRÓ- POLE DE SÃO PAULO}

A identificação dos compartimentos ambientais estruturantes na macrometrópole de São Paulo aqui apresentada tem apenas caráter exploratório, em face da escala tra- 
balhada e dos objetivos assumidos na hipótese da pesquisa ${ }^{4}$, da qual este artigo é um pequeno recorte. Não se pretendeu elaborar um mapeamento preciso da área de cada compartimento, bem como de seus limites divisórios com outros compartimentos. Na leitura estratégica do relevo, para a identificação dos compartimentos ambientais estruturantes da paisagem, observou-se o critério de identificar os conjuntos indutores e os receptores de processos das dinâmicas do clima e água. Num segundo momento, verificou-se a extensão de cada conjunto ou compartimento, e a sua área de influência, principalmente no que tange à dinâmica da água, especialmente a do escoamento superficial.

Para identificar os principais compartimentos ambientais indutores de processos naturais, ou seja, aqueles potencializadores da intensidade desses processos em face da energia que dissipa, foram levantados os principais divisores de água das bacias hidrográficas existentes na área estudada, sobretudo aqueles onde se encontram maiores altitudes e desníveis topográficos. Portanto são os divisores de água compostos pelos alinhamentos serranos e/ou de topo de morrarias que compõem uma parte desse quadro das linhas estruturantes de uma paisagem.

Mas não são todos os divisores que satisfazem essas exigências de altitude e desnível topográfico mais pronunciado. Aliam-se, a esses dois elementos, a extensão do alinhamento do divisor pela paisagem, e a área de influência de seus efeitos. Assim, incorporam-se a esses compartimentos ambientais estruturantes as principais áreas de concentração de nascentes, os principais anfiteatros de nascentes, e os principais alinhamentos que as unem. Dessa forma, teremos satisfeitas exigências ecológicas de corredores que interligam essas áreas de concentração de nascentes. Os limites desses compartimentos de topo, quando mapeados em escala apropriada, serão dados pelas linhas de ruptura de declividade das vertentes, que incorporem os setores de topo e das encostas de alta declividade.

De outro lado, atentou-se para as principais áreas receptoras de processos naturais induzidos de outros compartimentos mais elevados. Nesse sentido, o olhar se direcionou aos fundos de vale, ou seja, para as áreas mais baixas do relevo, baixas no sentido relativo, pois em relação ao entorno imediato dessas áreas. Assim, reconhecem-se

4 Trata-se da tese de doutorado apresentada à FFLCH/USP, em 2012, sob o título "Dispersão urbana e apropriação do relevo na macrometrópole de São Paulo". 
os principais canais de drenagem da rede hidrográfica local e regional, ou seja, os canais coletores de cada bacia ou sub-bacia. Dessa forma, tem-se o segundo conjunto de linhas estruturantes da paisagem.

Os mapas das figuras 2 e 3 visam ilustrar esses elementos estruturantes da paisagem da área da macrometrópole de São Paulo. Para melhor visualização, optou-se pela utilização de uma base antiga, porém de fácil leitura. Trata-se de uma figura, publica-

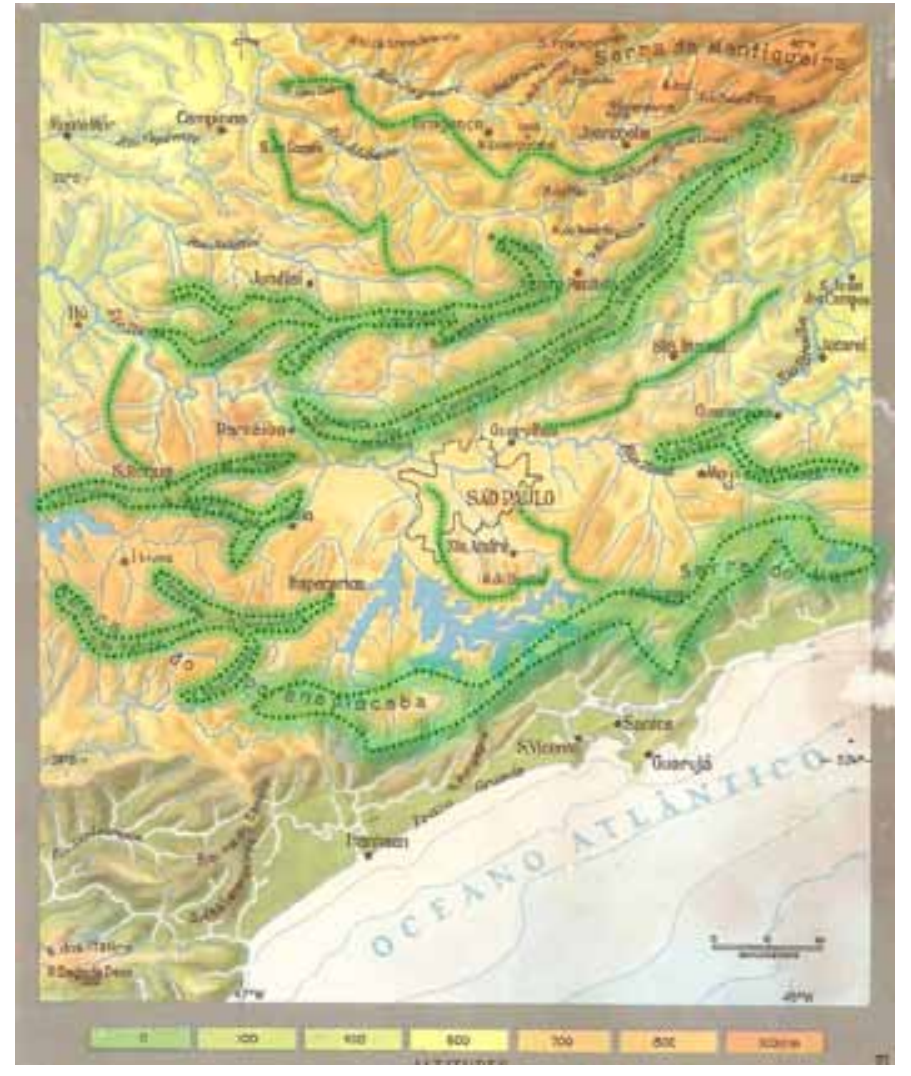

Figura 2 - Desenho esquemático dos principais compartimentos ambientais estruturantes da paisagem - lineamento de divisores de água. Fonte: Azevedo (1958), adaptado pelo autor. da em 1958, no livro "A cidade de São Paulo: estudos de geografia urbana", organizado por Aroldo de Azevedo, referente ao mapa hipsométrico da região de São Paulo e áreas vizinhas. No mapa da Figura 2, estão representados os principais compartimentos ambientais estruturantes que assumem uma posição de indutores de processos da natureza que perpassam pela superfície. Como já mencionado, trata-se dos principais divisores de água do relevo, que delimitam as bacias hidrográficas aí existentes. Neste mapa, já é possível perceber que alguns destes compartimentos são mais expressivos, pois formam um lineamento mais contínuo e longo, e também apresentam uma largura mais pronunciada.

Nesse sentido, pode ser destacado o conjunto de serras que formam os contrafortes da serra do Mar e o conjunto da serra da Cantareira. Os contrafortes da serra do Mar constituem-se em uma borda de planalto cujos divisores estão alinhados entre 750 e 850 metros de altitude. Forma toda a borda sul-sudeste da bacia do Alto Tietê, onde nascem os principais rios que drenam a região de São Paulo. Essas cabeceiras de drenagem se estendem por aproximadamente $140 \mathrm{~km}$, de Salesópolis a Embu-Guaçu. 
Já o conjunto formado pela serra da Cantareira, serra do Itaberaba e serra da Pedra Branca, passando pelo setor do pico do Jaraguá e morro Botucavaru, na região de Alphaville, caracteriza-se por um expressivo lineamento serrano, que se estende por aproximadamente $90 \mathrm{~km}$, desde Piracaia - Igaratá, até Barueri. A altitude média fica em torno de $1.100 \mathrm{~m}$ (Cantareira, Jaraguá). A serra do Itaberaba apresenta as maiores elevações, em torno de $1.300 \mathrm{~m}$, enquanto a serra de Pedra Branca se situa em torno de 1.000 metros. Na região de Alphaville, o morro do Botucavaru se nivela em torno de 800 a 900 metros.

Um terceiro conjunto expressivo de lineamento de divisores pode ser reconhecido entre os rios Tietê - Juqueri e Jundiaí. É formado pelo conjunto de serras que se estende desde Atibaia até Jundiaí, separadas por colos estreitos ou mais alongados, mas que formam um mesmo alinhamento, constituído pelas serras da Pedra Vermelha, do Boturuju, Juqueri, dos Cristais e do Japi. As altitudes começam em torno de $1.200 \mathrm{~m}$, na serra da Pedra Vermelha, decaem para $1.100 \mathrm{~m}$, na serra do Juqueri, ficam em torno de $1.000 \mathrm{~m}$, nas serras do Boturuju e dos Cristais, e se elevam novamente para 1.200 $\mathrm{m}$, na serra do Japi.

Influências estruturais impostas pela história geológica do embasamento cristalino do planalto Atlântico, nessa região, colaboraram para a configuração de uma rede de drenagem de tipo retangular, em alguns setores que apresentam interflúvios pouco distantes. Isto pode ser observado nos divisores de água das bacias dos rios Atibaia e Jaguari; e entre o rio Atibaia e o rio Jundiaí. Como se pode observar no mapa da Figura 2 , esses divisores formam lineamentos razoavelmente extensos, porém estreitos. Formam compartimentos ambientais localmente importantes para os municípios de Atibaia, Bragança Paulista, Itatiba, Campo Limpo Paulista, Jarinu, Jundiaí, Louveira e Vinhedo.

O divisor de águas dos rios Atibaia e Jaguari é formado por algumas serras conhecidas localmente por serra do Juncal, entre Piracaia e Joanópolis; montanha Leite Sol, em Bragança Paulista; e serra das Cabras, em Morungaba. As altitudes vão declinando, desde os 1.000-1.100 metros, na região das cabeceiras em Piracaia e Bragança Paulista; entre 900 e 1.000 metros na serra das Cabras; declinando consideravelmente, quando deixa os terrenos cristalinos e adentra a depressão Periférica, ficando entre 600 e 700 metros na região de Jaguariúna.

As principais serras dessa região estudada, assim como os principais divisores de água das bacias que drenam esse território, apresentam forte controle estrutural, de- 
rivado da presença de falhas ou saliências de intrusões graníticas. Além disso, a provável existência de dois ciclos erosivos antigos de aplainamento da superfície foram objeto de investigação de muitos geólogos e geomorfólogos, e estão relatados nas obras de Almeida (1958) e Ab'Saber (1958), dentre outros. O nivelamento das cristas dos principais divisores de água dessa região do planalto Atlântico sugere a existência, na história dessa paisagem, de uma superfície de aplainamento em torno dos 1.100 metros, e outra nivelada na faixa dos 800 metros, cujos topos se confundem com os das camadas terciárias da bacia sedimentar de São Paulo.

A maior parte do conjunto de serras que ocorre nessa região da macrometrópole de São Paulo tem constituição granítica, e tem suas cristas niveladas a $1.100 \pm 50$ metros. O conjunto litológico do planalto Atlântico, nessa região, apresenta-se dominado por rochas graníticas e numerosas intercalações de xistos e gnaisses, restos do teto do batólito granítico, que, devido à erosão diferencial de resistência dessas rochas, ressaltou na paisagem a presença desses conjuntos serranos graníticos.

Cabe salientar que os terrenos derivados da decomposição de rochas graníticas apresentam solo de alteração de rocha altamente suscetível à erosão, quando exposto por cortes em obras viárias e de edificação, sem o tratamento adequado. Assim, em face das declividades das vertentes, preponderantemente elevadas nessas regiões serranas, ou em suas morrarias do entorno, não é recomendada a ocupação urbana, sobretudo para loteamentos para a população de baixa renda, realizados com intenso parcelamento, em lotes pequenos.

Em termos de expressão territorial de sua influência na dinâmica da água e na circulação atmosférica, dentre outros fatores naturais e socioambientais, o alinhamento de divisores das serras da Cantareira, do Itaberaba e da Pedra Grande, incluindo os morros do Jaraguá e do Botucavaru, constitui um dos principais compartimentos ambientais da região central da macrometrópole de São Paulo.

Não cabe aqui detalhar suas características físicas, e nem sua expressividade nas implicações ambientais do território, pois estas já são bem conhecidas. Acrescente-se o fato de que boa parte de sua extensão já se encontra sob proteção legal, por meio da criação de unidades de conservação. $O$ decreto $n^{\circ}$ 55.662/2010, de criação do Parque Estadual de Itaberaba, Parque Estadual de Itapetinga, Floresta Estadual de Guarulhos e Monumento Natural Estadual da Pedra Grande, já salienta a importância desses divisores para a região, ao afirmar a relevância do setor norte-nordeste da 
serra da Cantareira, para a conservação da biodiversidade, pois, ao longo das últimas décadas, tem sido objeto de inúmeros estudos, que ressaltam a importância do Corredor Cantareira - Mantiqueira, para a conectividade da flora e da fauna, e pela necessidade de proteção de seus recursos hídricos.

No mapa da Figura 3, estão representados os principais compartimentos ambientais estruturantes que assumem dominantemente uma posição de receptores de processos da natureza que perpassam pela superfície. Aqui estão identificados os principais canais de drenagem da região, ou seja, os principais rios que dão nome às bacias e sub-bacias hidrográficas que drenam essa região do planalto Atlântico e da depressão Periférica. Estão representados apenas os lineamentos principais, e não a sua expressão em área, seja de planície aluvial ou de fundo de vale, em face de que a escala do mapa não permite uma identificação mais efetiva da área do compartimento, também pelo fato das sutis diferenças que nele ocorrem, em suas configurações de várzeas e terraços de diferentes matizes e gênese. Os dois compartimentos mais relevantes e sensíveis aos processos naturais e urbanos na macrometrópole são os eixos formados pelo rio Tietê e pelo rio Paraíba do Sul, embora o primeiro assuma uma condição de centralidade muito mais relevante, em termos da ocupação metropolitana.

Figura 3 - Desenho esquemático dos principais compartimentos ambientais estruturantes da paisagem - lineamento de fundos de vale. Fonte: Azevedo (1958), adaptado pelo autor.

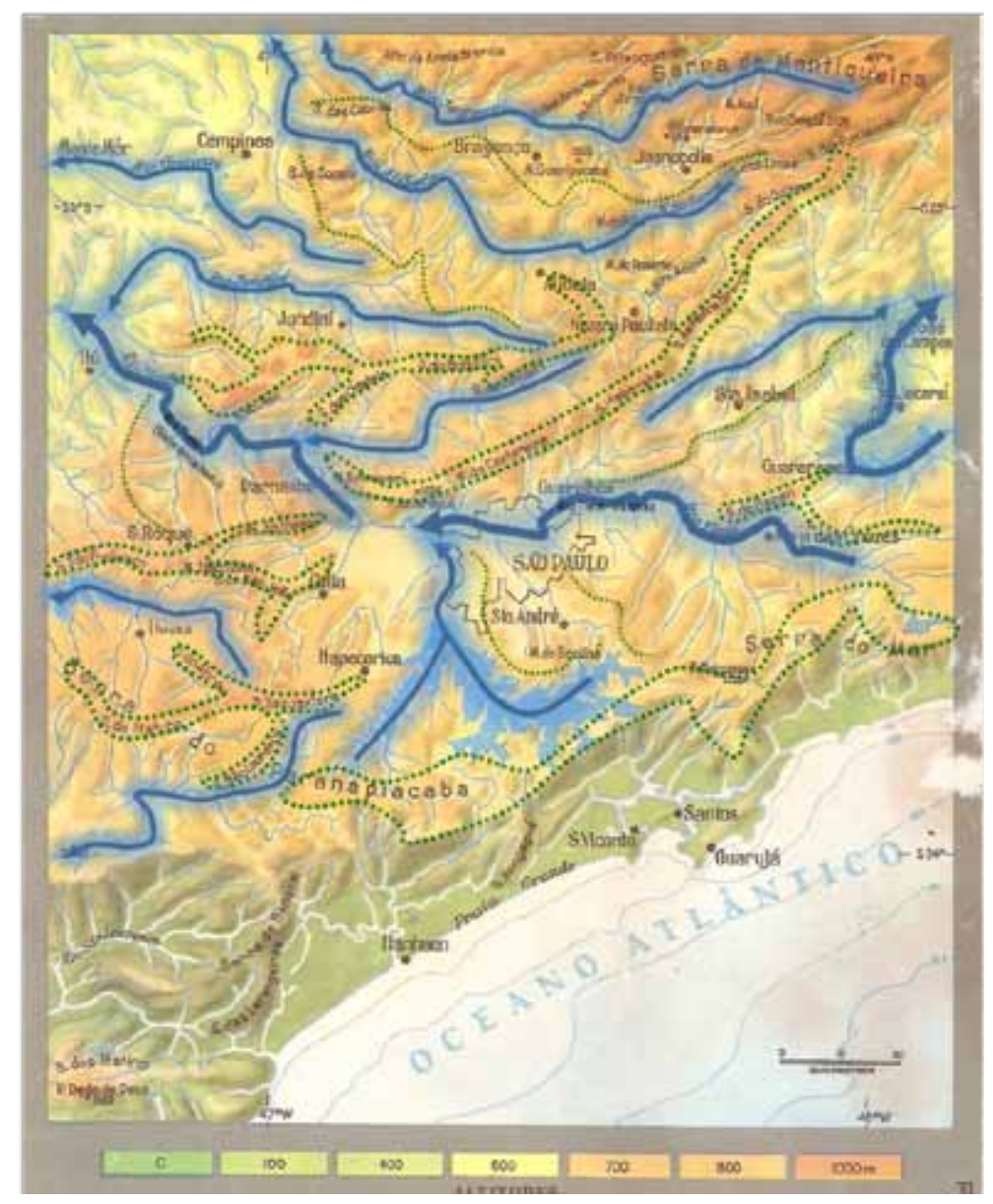


Os rios representados no mapa se constituem nos principais setores de fragilidade ambiental do território como um todo, mas particularmente do entorno das regiões que drenam, e das quais sofrem impactos diretos, tanto derivados da ocupação urbana, como da rural. Como se trata de uma região densamente povoada, os impactos relativos ao uso urbano são mais intensos. Das fragilidades, há que ressaltar os riscos da relação entre a ocupação dos setores de várzeas, terraços e das planícies aluviais restritas, e a administração da vazão desses cursos, que colocam espaços urbanos em prováveis situações de enchentes, durante os cada vez mais concentrados eventos chuvosos. Basta lembrar os recentes e frequentes casos ocorridos no setor de várzeas do Tietê (Jd. Pantanal) e seus afluentes, como o Aricanduva e Tamanduateí, além do ocorrido em Caieiras, com as cheias do Juqueri.

Aárea de influência desses compartimentos ambientais estruturantes é a própria área da bacia que drenam, por isso, os compartimentos mais importantes e relevantes ao ordenamento ambiental são os dois principais coletores de suas bacias, o rio Tietê e o rio Paraíba. Os dois possuem parte de seu curso em áreas de fundo de vale encaixado nas vertentes inclinadas das colinas, morros e serras da região, onde adquirem velocidade maior em sua corrente d'água, que muitas vezes se transformaram em potencial de represamento para produção de água potável e de energia. Ambos possuem, também, parte de seu percurso aninhado em planícies aluviais mais expressivas, que formaram setores significativos de várzeas e de terraços, sítio este muito utilizado para a ocupação urbana.

Outros três cursos d'água possuem expressividade na região, em termos de área drenada, mas também em termos de impactos da urbanização, que se densificou ao extremo nas três últimas décadas. São eles os rios Pinheiros, Jundiaí e Atibaia.

O rio Pinheiros, já historicamente utilizado para a produção de energia e água potável, teve o fundo de seu vale e de seus formadores utilizado para represamento, a partir da década de 1910 (represa Guarapiranga, construída em 1907). No final da década de 1920, é formada a represa Billings, com o represamento dos afluentes Jurubatuba, rio Grande e rio Pequeno.

Já o rio Jundiaí, em seu pequeno curso de aproximadamente $70 \mathrm{~km}$, passa pela área urbana de cinco cidades - Campo Limpo Paulista, Várzea Paulista, Jundiaí, Itupeva e Indaiatuba -, antes de desaguar no rio Tietê. É praticamente um rio urbano, tendo 
poucos trechos de seu percurso livres de ocupação de suas margens. O mais grave é que apresenta uma razoável planície aluvial, em boa parte também ocupada pela mancha urbana dessas cidades. Trata-se de um compartimento ambiental importante, em termos locais.

O rio Atibaia se estende por aproximadamente $130 \mathrm{~km}$, e passa lateralmente por cinco cidades, em seu alto e médio curso (Nazaré Paulista, Bom Jesus dos Perdões, Atibaia, Itatiba e periferia de Campinas). Sua planície aluvial mais expressiva, embora de pequena dimensão, ocorre entre Bom Jesus dos Perdões e Atibaia. Deve ser considerado um compartimento ambiental estruturante, em face de sua extensão e área, e também pelo avanço expressivo da ocupação de loteamentos dispersos (condomínios), às suas margens.

Embora com menor dimensão, aproximadamente $55 \mathrm{~km}$ de extensão, o rio Juqueri drena uma área importante, de aproximadamente $800 \mathrm{~km}^{2}$. Trata-se do coletor principal de uma importante área de nascentes, confinado pelas serras da Cantareira, de um lado, e do Juqueri, Pedra Vermelha e Boturuju, de outro. Hoje pode ser considerado um compartimento ambiental estruturante, não só local, mas regionalmente, em face de sua posição muito próxima da metrópole, e por ser um importante manancial de abastecimento para a metrópole de São Paulo. A amplitude topográfica entre divisores e fundo de vale é expressiva, o que denota a existência de setores de vertentes de alta declividade, em área considerável. Abriga, também, um represamento formado pela represa Paiva Castro, da Sabesp. As vertentes que drena são alvo de pressão imobiliária, por ocupação de condomínios fechados de alta e média renda. Passa lateralmente pelas áreas urbanas das cidades de Mairiporã, Franco da Rocha, Caieiras, e bairros dispersos de Cajamar e Santana de Parnaíba, antes de desaguar no rio Tietê.

Alguns desses compartimentos citados já recebem alguma regulação legal. No nível estadual, apenas a várzea do Embu (Embu Guaçu) teve parte do trecho do rio preservada de ocupação (128 ha), como parque estadual, segundo tipologia do SNUC. As demais áreas são reguladas por APAs - áreas de proteção ambiental -, que permitem uma série de tipologias de uso, e dependentes, para sua real proteção, de fiscalização e controle sistemático e firme do Estado, o que, sabe-se, nem sempre acontece a contento da preservação necessária, também por abranger áreas de grande povoamento e de interesses comerciais e imobiliários. 


\section{CONSIDERAÇÕES FINAIS}

Esta análise ambiental estratégica do relevo induz-nos a refletir sobre as formas de ocupação do território que vêm se dando historicamente na macrometrópole de São Paulo e em outras regiões metropolitanas. Tanto os aspectos físicos da natureza, materializados no relevo e sobre ele, como os aspectos da urbanização abrangem matrizes que se configuram em espaços nitidamente lineares, ou em areolares, mas que são intrinsecamente interdependentes. Neste artigo, colocaram-se em destaque as principais linhas estruturantes de uma paisagem, as dispersoras e as receptoras de processos, que foram e são objeto de interesse de instalação das infraestruturas primordiais na urbanização do território, ou seja, as infraestruturas de mobilidade

Seja na escala regional, seja na local, os fundos de vale, com suas planícies aluviais ou vales encaixados, foram e são ainda setores de relevo preferenciais, para a implantação dos caminhos de mobilidade - rodovias, avenidas, ruas, estradas de ferro -, que reduzem sua eficiência no desempenho de suas funções reguladoras dos processos naturais, sobretudo agora, em face da pressão cada vez mais intensa que os processos urbanos Ihes impõem.

De outro lado, os divisores de água, que também conformam lineamentos paisagísticos e apresentam potencialidades estratégicas relevantes em termos ambientais, foram objeto de ocupação por diversas estruturas urbanas, valendo lembrar as estradas e avenidas utilizadas como eixos de penetração/expansão urbana, em que a cidade se estendia pelas vertentes, pressionando e ocupando os setores de nascentes.

Pensar estrategicamente o relevo, na atualidade, requer outra reflexão sobre os espaços de implantação das estruturas urbanas em geral, e, dentre elas, as de mobilidade, a fim de que se possam preservar minimamente os principais compartimentos ambientais estruturantes de uma paisagem. 


\section{REFERÊNCIAS BIBLIOGRÁFICAS}

AB'SABER, A.N. O sítio urbano de São Paulo. In: AZEVEDO, Aroldo de (Org.). A cidade de São Paulo - Estudos de Geografia Urbana, v.1.. São Paulo: Cia. Edt. Nacional, 1958.

. Um conceito de geomorfologia a serviço das pesquisas sobre o Quaternário. In: Geomorfologia, 18. São Paulo: IGEOG/USP, 1969.

Formas de relevo: Texto básico. São Paulo: Edart, 1975.

ALMEIDA, F.F.M. O planalto paulistano. In: AZEVEDO, Aroldo de (Org.). A cidade de São Paulo - Estudos de Geografia Urbana, v. 1. São Paulo: Cia. Edt. Nacional, 1958.

AZEVEDO, A. (Org). A cidade de São Paulo: Estudos de geografia urbana. São Paulo: Cia. Edt. Nacional, 1958.

GODOY, J.F. (1826-1902). A província de São Paulo: Trabalho estatístico, histórico e noticioso. São Paulo: Imprensa Oficial do Estado de São Paulo/FUNDAP, 2007. (Edição fac-simile de 1875.)

IPT/SP. Mapa geomorfológico do Estado de São Paulo (1:500.000). São Paulo: IPT, 1981.

MONTE-MÓR, R.L. Urbanização extensiva e lógicas do povoamento: Um olhar ambiental. In: SANTOS, Milton; SOUZA, Maria Adélia A. de; SIVEIRA, Maria Laura. Território, globalização e fragmentação. São Paulo: Hucitec/Anpur, 1994.

ROSS, J.L.S.; MOROZ, I.C. Mapa geomorfológico do Estado de São Paulo. In: Revista do Depto. de Geografia, São Paulo, n. 10, 1996.

SANTOS, M. Metamorfoses do espaço habitado. São Paulo: Hucitec, 1988.

; SILVEIRA, Maria Laura. O Brasil: Território e sociedade no início do século XXI. Rio de Janeiro: Record, 2008.

SCHUTZER, J.G. Cidade e meio ambiente: A apropriação do relevo no desenho ambiental urbano. São Paulo: Edusp, 2012. 
SOJA, E.W. O desenvolvimento metropolitano pós-moderno nos EUA: virando Los Angeles pelo avesso. In: SANTOS, M.; SOUZA, M.A.; SILVEIRA, M.L. (Orgs.). Território, globalização e fragmentação. São Paulo: Hucitec, 1994.

TRICART, J. Ecodinâmica. Rio de Janeiro: IBGE/Supren, 1977. 